\title{
Topical Tacrolimus vs Topical Triamcinolone equally effective in the Treatment of Oral Lichen Planus
}

\author{
SAMAN MALIK ${ }^{1}$, FAIQA HASSAN ${ }^{2}$, USMAN UL HAQ ${ }^{3}$, WAJEEHA JABEEN ${ }^{4}$, FAROOQ ${ }^{5}$, SAQIB GHAFOOR KAYANI ${ }^{6}$ \\ ${ }_{1,2,3}$ Assistant Professor, Oral Biology, HITEC-IMS Dental College, Taxila Cantt. \\ ${ }^{4}$ Assistant Professor, Periodontology, HITEC-IMS Dental College, Taxila Cantt. \\ ${ }^{5}$ Assistant Professor Oral Medicine, Avicenna Dental College Lahore \\ ${ }^{6}$ Assistant Professor/HOD Oral Medicine, Watim Medical \& Dental College Rawalpindi \\ Correspondence to Dr. Saman Malik, Email: Somey_hassan@hotmail.com, Cell: 0312-3456303;
}

\begin{abstract}
Background: Lichen planus is a disease that can involve either skin, mucosa or both. Although there is no definite treatment but many medications are available for the relieving the symptoms of this autoimmune disease and recent literature has brought into light the use of an immunosuppressant such as Tacrolimus that may be effectively used as topical application in treatment of Oral Lichen Planus (OLP).

Methods: We conducted a study on 80 patients to determine the use of results of topical Tacrolimus ( $0.1 \%)$ versus Triamcinolone acetonide $(0.1 \%)$ ointment for the treatment of Oral Lichen Planus over a period of six months at Oral \& Maxillofacial Surgery Department, HITEC Dental College Taxila.

Results: Outcome of the study was determined in terms of 'Improvement in pain'.

Conclusion: This study showed an insignificant difference in improvement in pain of patients of lichen planus treated with tacrolimus and triamcinolone.

Keywords: Oral lichenplanus, treatment outcome, symptomatic management, improvement in pain,
\end{abstract}

\section{INTRODUCTION}

Lichen planus (LP) is benign autoimmune inflammatory muco-cutaneous disease, muco meaning mucosa and cutaneous meaning $\operatorname{skin}^{1,2,3}$. Although lichen planus involves skin and mucosa both but it's not necessary that oral lesions are accompanied by lesion on any other mucocutaneous area. The exact etiology of lichen planus is still to be ruled out but it is considered that immune system of body is basically involved in its pathogensis ${ }^{2,3}$. There are many factors that contribute to its occurrence including infectious agents such as human papilloma virus, helicobacter, Epstein barr virus, drugs such as beta blockers, tooth paste flavoring agents, antimalarial, food additives. Stress, trauma, cigarette smoking are also some of the contributing factors in initiation of this disease that leads to activation of $T$ cells as well as CD 8 cells of immune system resulting in cell death of oral epithelium ${ }^{3}$. Clinical presentation of Oral lichen planus is much different from that of skin and in oral cavity. This disease presents in six different forms which ranging from lacy white streaks pattern to white plaques to eroded ulcers ${ }^{2,5,6}$. The white lacy striated lesions of oral mucosa are usually asymptomatic while those which erodes elicit burning sensation and soreness $2,4,7$. The reticular, erosive/atrophic and plaque type are symptomatic. They appear on buccal mucosa, tongue, gingiva, palate, lips and retro molar pad area $^{2,7,8}$. It can affects approximately $0.1-4 \%$ of middle aged general population and females are affected more than males $2,3,5,9$.

Lichen planus is a recurrent lesion in which there is a periods of exacerbation with increased erythema or erosions with intense pain and burning sensation ${ }^{4}$. During periods of quiescence, there is reduction in severity of clinical sign and symptoms, but the disease has a tendency

Received on 27-01-2021

Accepted on 03-06-202 to relapse ${ }^{2}$. The diagnosis of Oral lichen planus is based on history, clinical evaluation and on detailed investigation including immunohistochemistry studies carried out on biopsy sample 4,3 . Normal histology of oral mucosal epithelium is made up of five layers: strateum cornium, stratum lucidum, stratum granulosum, stratum spinosum and basal layer (separates epithelium from lamina propria). Results of histopathology of lichen planus lesion often show variation in epithelial thickness, destruction of basal layer of cell and infiltration of mononuclear cells in the lamina propria ${ }^{2,6}$.

The World Health Organization has considered OLP as precancerous ailment which is "a generalized state related with a much increased tendency to transform into cancerous lesion and its malignant transformation rateof $5.3 \% \%^{4,5,6}$. Treatment of symptomatic OLP includes medical treatment with corticosteroids, retinoids, calcineurin inhibitors either topically or systematically, UV, phototherapy, lasers, surgery and miscellaneous $2,9,10$. It is preferred to advise topical drug application initially as this method of treatment has limited side effect ${ }^{13}$. The drug of choice for the treatment of OLP is application of topical corticosteroids. Triamcinolone 0.1 to $0.2 \%$ cream when applied has greater tenacity to mucosa so drugs is available for longer time ${ }^{14}$. Although corticosteroids are good anti-inflammatory drugs and helps in reducing edema and lymphocytic exudation, prevents swelling and cell damage by inhibiting phagocytosis tissue damage and fibrosis, recent evidences also suggested that an immunosuppressant such as Tacrolimus belonging to macrolide family may effectively be used topically in treatment of Oral Lichen Planus ${ }^{13}$.

So we conducted a study to compare the difference in the result of topical Tacrolimus $(0.1 \%)$ ointment $(\mathrm{T})$ versus Triamcinolone acetonide (TA) $(0.1 \%)$ orabase for the symptomatic treatment of Oral Lichen Planus. 


\section{MATERIAL AND METHODS}

A sample size of 80 patients with clinical diagnosis of painful OLP was included in this study which was conducted at Oral Maxillofacial department HITEC Dental College after approval from Ethical Review Board. The sample was then divided into two equal sub-groups namely Group A (receiving the topical application of $0.1 \%$ Tacrolimus ointment, 4 times daily for 12 weeks) and Group B (receiving the topical application of $0.1 \%$ Triamcinolone acetonide ointment, 4 times daily for 12 weeks) using lottery method. Severity of the disease at the time of presentation was assessed using Visual Analogue Scale (VAS) for pain 0-3. All the patients were instructed to use the respective drug as prescribed (4 times daily application). All patients were then reviewed at $2^{\text {nd }} t$, 4 th, 8th and finally on 12th weeks. The final outcome of the drug use was recorded at the end of 12th week only using VAS and any degree of decrease in VAS from baseline VAS (at the time of presentation) was considered improvement.

\section{RESULTS}

Data was analyzed by SPSS version 11.0 .80 patients were included in the study according to inclusion criteria of the study. Patients were randomly divided into two equal groups. Group A was given manual application of $0.1 \%$ tacrolimus in orabase on the affected oral mucosa 4 times a day, for 12 weeks whereas Group B was given manual application of $0.1 \%$ triamcinolone in orabase on the affected oral mucosa 4 times a day, for 12 weeks.

Sampling technique: Non-probability purposive sampling Inclusion criteria

1. Age $\geq 18$ years

2. Both genders.

3. Patients with clinical and histopathological diagnosed oral lichen planus of any type (reticular, erosive, eroded, plaque like, white)

4. Presence of any type of painful OLP lesions with a VAS $=1$ or greater.

5. Patients that have not undergone any previous treatment for OLP

\section{Exclusion criteria:}

1. Patients with history of HIV (AIDS) diagnosed on medical record

2. Patients on systemic steroid therapy diagnosed on history

3. Dysplasia on Histopathology report

4. Patients allergic to macrolide drugs diagnosed on history

5. Pregnant patients diagnosed on history

6. Lactating mothers diagnosed on history

Out of 80 patients in the study $75 \%$ percent were females and only $25 \%$ percent were males and included age range from 42 to 68 years with the mean being 52.85 years. Mean age in group A (Tacrolimus) was $53.45 \pm 6.34$, out of which $72.5 \%$ were females whereas in Group B (triamcinolone) mean age was $52.25 \pm 5.58$ and $77.5 \%$ percent of the patients were female.

Outcome of the study was determined in terms of relieve of pain and healing. Any decrease in Visual Analogue Scale was termed as improvement.
On $2^{\text {nd }}$ week follow up, improvement in symptoms was assessed, 31/40 (77.5\%) patients got improvement in symptoms in Group A which was given tacrolimus and $36 / 40$ (90\%) patient got improvement in Group B which was given triamcinolone.

On $8^{\text {th }}$ week follow-up, patients were assessed, 27/40 $(67.5 \%)$ patients have improvement in Group A and 30/40 (75\%) got improvement in symptoms in Group B.

On $12^{\text {th }}$ week, improvement in symptoms was assessed, in which symptoms were relieved in 31/40 $(77.5 \%)$ patients in Group A and 36/40 (90\%) patients got improved in Group B.

Table 1: Descriptive statics of age in both groups
\begin{tabular}{|l|l|l|l|}
\hline \multicolumn{2}{|c|}{ Group I } & \multicolumn{2}{c|}{ Group $\mathbf{2}$} \\
\hline Mean & 53.45 & Mean & $\mathbf{5 2 . 2 5}$ \\
\hline Std. deviation & 6.341 & Std, deviation & 5.583 \\
\hline Minimum & 42 & Minimum & 45 \\
\hline Maximum & 65 & Maximum & 68 \\
\hline
\end{tabular}

Table 2: Comparison of gender in both groups

\begin{tabular}{|l|l|l|l|}
\hline \multicolumn{2}{|c|}{ Group I } & \multicolumn{2}{c|}{ Group 2 } \\
\hline Male & Female & Male & Female \\
\hline $11(27.5 \%)$ & $29(72.5 \%)$ & $9(22.5 \%)$ & $31(77.5 \%)$ \\
\hline
\end{tabular}

Table 3: Improvement in pain at $2^{\text {nd }}$ week follow up

\begin{tabular}{|l|l|l|l|l|}
\hline Category & Group A & $\%$ & Group B & $\%$ \\
\hline Yes & 31 & 77.5 & 36 & 90 \\
\hline No & 9 & 22.5 & 4 & 10 \\
\hline
\end{tabular}

Table 4: Improvement in pain at $8^{\text {th }}$ week follow up

\begin{tabular}{|l|l|l|l|l|}
\hline Category & Group A & $\%$ & Group B & $\%$ \\
\hline Yes & 27 & 67.5 & 30 & 75 \\
\hline No & 13 & 5.2 & 10 & 25 \\
\hline
\end{tabular}

Table 5: Improvement in Pain in $12^{\text {th }}$ week follow-up

Table 5: Improvement in Pain in $12^{\text {th }}$ week follow-up
\begin{tabular}{|l|l|l|l|l|}
\hline Category & Group A & $\%$ & Group B & $\%$ \\
\hline Yes & 31 & 77.5 & 36 & 90 \\
\hline No & 9 & 22.5 & 4 & 10 \\
\hline
\end{tabular}

\section{DISCUSSION}

Our study was aimed at comparing the treatment outcome of use of topical Triamcinolone acetonide ointment with topical Tacrolimus ointment in patients suffering from Oral Lichen Planus. Triamcinolone is being widely used and corticosteroids are till date the first line therapy for Oral lichen planus ${ }^{15}$. Recent studies and investigations suggests that immunosuppressant drugs such as Tacrolimus can be very effectively used in the treatment of this diseases in shown by $R$ Laeijendecker ${ }^{16,17}$.

In our study a total of 80 patients were enrolled. It consisted of $75 \%$ female and $25 \%$ male patients. It is a documented fact that females are more commonly affected by OLP than males and such has been confirmed by studies in the past ${ }^{2,15}$. Our study reflected gender predilection of female to male ratio of $3: 1$ which is close to female to male gender predilection of $4: 1$ in reported study by Qazi JA andByrd JA ${ }^{2,15}$.

The mean age of our study was $53.45 \pm$ SD 6.34 years in Group A with minimum and maximum age was 42 and 65 years, whereas mean \pm SD of age in Group B was $52.25 \pm 5.58$ with ranges from 45 to 68 years. These value were close to but higher than the national as well as international figures in studies by: Qazi $\mathrm{JA}^{3}$. This outcome can be supported by the statement given by Gupta $S$ who 
stated that oral Lichan planus affects the persons with age range between $30-60$ years ${ }^{18}$. Another study by Byrd JA showed age range 38 to 82 which is a bit more than our age range ${ }^{15}$.

The outcome of our study was measured in terms of improvement in pain on visual analogue scale (VAS) from the initial pain on VAS at the time of presentation. After 2 weeks of therapy our group one receiving triamcinolone, $20 \%$ of patient showed improvement and those receiving Tacrolimus $30 \%$ showed improvement in symptoms. A study conducted by Sonthalia S showed almost similar results having $20 \%$ patient showing good response to steroids and $25 \%$ patients showed good response to Tacrolimus which is closer percentage to our $30 \%{ }^{14}$. After 8 weeks of therapy, $60 \%(24 / 40)$ of patients that received topical Triamcinolone therapy reported improvement in pain which is more than the study by Sonthalia S, while $75 \%$ (30/40) of patients that received topical Tacrolimus therapy reported improvement in pain which is nearly equal to $70 \%$ shown by Sonthalia S study ${ }^{14}$. After 12 weeks Sonthalia S showed $90 \%$ patients with partial or complete response with steroids and $95 \%$ patients improved symptoms with Tacrolimus. These results were similar to our findings at $12^{\text {th }}$ week which were $85 \%$ with triamcinolone and $93 \%$ with Tacrolimus. These results show there is not much difference in the outcome of the two drug therapies. Similar facts were reported by Laeijendecker $R$ as in his study topical tacrolimus $0.1 \%$ ointment resulted in a better response than triamcinolone acetonide $0.1 \%$ ointment. Sonthalia S study results also supported the use of Tacrolimus is quite effective in treatment of Oral Lichen planus $^{14}$. Arunkumar S study showed that Topical application of pimecrolimus $1 \%$ cream showed better results than triamcinolone acetonide $0.1 \%$ oral paste in patients with symptomatic OLP similar to our results ${ }^{19}$. The study conducted by Qazi JA showed that $88 \%$ percent of patients showed improvement when treated with tacrolimus as compared to $46 \%$ patients who showed improvement when treated with triamcinolone. He also found out that Tacrolimus induced a better therapeutic response as compared to triamcinolone but recurrence was common ${ }^{2}$. Our study similarly shows $95 \%$ that showed improvement in pain when treated with Tacrolimus but our study showed that almost same number that is $90 \%$ showed improvement with triamcinolone which is much more than that of $46 \%$ showed by Qazi JA2. M Siponen also demonstrated insignificant difference in the outcome of use of both drugs so it supports our suggestion of using Tacrolimus. Similar to our outcome Lozada-Nur et al outcome of Tacrolimus in terms of pain management and healing of the lesion were found out significant and that tacrolimus was statistically important in treating patients with OLP ${ }^{21}$.

\section{CONCLUSION}

This study showed an insignificant difference in improvement in pain of patients of oral lichen planus treated with topical Tacrolimus and in patients treated with topical triamcinolone and further research is warranted.

\section{Conflict of interest: Nil}

\section{REFERENCES}

1. Ahmed, S., Prodhan, M. R., Rezwana, R., Afroz, J., Ahmad, M., \& Khan, M. R. (2018). Comparison between uses of topical tacrolimus and triamcinolone ointment for the treatment of oral lichen planus. Update Dental College Journal, 8(1), 17-21

2. Qazi JA. Treatment Of Oral Lichen Planus With Topical Tacrolimus And Triamcinolone Acetonide Ointment--A Comparative Study. Pakistan Oral \& Dental Journal. 2010 Jun 1;30(1).

3. Gupta S, Jawanda MK. Oral lichen planus: An update on etiology, pathogenesis, clinical presentation, diagnosis and management. Indian journal of dermatology. 2015 May;60(3):222.

4. Sivaraman S, Santham K, Nelson A, Laliytha B, Azhalvel P, Deepak $\mathrm{JH}$. A randomized triple-blind clinical trial to compare the effectiveness of topical triamcinolone acetonate $(0.1 \%)$, clobetasol propionate $(0.05 \%)$, and tacrolimus orabase $(0.03 \%)$ in the management of oral lichen planus. Journal of pharmacy \& bioallied sciences. 2016 Oct;8(Suppl 1):S86

5. Thongprasom K, Carrozzo M, Furness S, Lodi G. Interventions for treating oral lichen planus. Cochrane Database of Systematic Reviews. 2011(7).

6. Shen ZY, Liu W, Zhu LK, Feng JQ, Tang GY, Zhou ZT. A retrospective clinicopathological study on oral lichen planus and malignant transformation: analysis of 518 cases. Medicina oral, patologia oral y cirugia bucal. 2012 Nov;17(6):e943.

7. Ahmed I, Nasreen $S$, Jehangir $U$, et al. Frequency of oral lichen planus in patients with noninsulin dependent diabetes mellitus. J Pak Assoc Dermatol. 2012;22:30-4.

8. Nosratzehi T. Oral lichen planus: an overview of potential risk factors, biomarkers and treatments. Asian Pacific journal of cancer prevention: APJCP. 2018;19(5):1161.

9. Peng $Q$, Zhang J, Ye X, Zhou G. Tumor-like microenvironment in oral lichen planus: evidence of malignant transformation?. Expert review of clinical immunology. 2017 Jun 3;13(6):635-43.

10. Carrozzo M, Thorpe R. Oral lichen planus: a review. Minerva stomatologica. 2009;58(10):519-37.

11. Caruntu C, Mitran M, Mitran C, Sarbu I, Rusu LC, Matei C, Constantin C, Neagu M, Georgescu SR. Markers of oral lichen planus malignant transformation. Disease markers. 2018 Feb 26;2018.

12. Drogoszewska B, Chomik P, Michcik A, Polcyn A. A standard picture of healthy oral mucosae by direct oral microscopy. Advances in Dermatology and Allergology/Postępy Dermatologii I Alergologii. 2013 Jun;30(3):159.

13. Piñas L, García-García A, Pérez-Sayáns M, Suárez-Fernández R, Alkhraisat $\mathrm{MH}$, Anitua $\mathrm{E}$. The use of topical corticosteroides in the treatment of oral lichen planus in Spain: A national survey. Medicina oral, patologia oral y cirugia bucal. 2017 May;22(3):e264.

14. Kini R, Nagaratna DV, Saha A, Praveen BN. Therapeutic management of oral lichen planus: A review for the clinicians. World $\mathrm{J}$ Dent. 2011;2(3):249-53

15. Sonthalia S, Singal A. Comparative efficacy of tacrolimus $0.1 \%$ ointment and clobetasol propionate $0.05 \%$ ointment in oral lichen planus: a randomized double- blind trial. International journal of dermatology. 2012 Nov;51(11):1371-8.

16. Laeijendecker R, Tank B, Dekker SK, Neumann HA. A comparison of treatment of oral lichen planus with topical tacrolimus and triamcinolone acetonide ointment. Acta dermato-venereologica. 2006 May 1;86(3):227-9.

17. Byrd JA, Davis MD, Bruce AJ, Drage LA, Rogers RS. Response of oral lichen planus to topical tacrolimus in 37 patients. Archives of dermatology. 2004 Dec 1;140(12):1508-12.

18. Gupta S, Jawanda MK. Oral lichen planus: An update on etiology, pathogenesis, clinical presentation, diagnosis and management. Indian journal of dermatology. 2015 May;60(3):222.

19. Arunkumar S, Kalappanavar AN, Annigeri RG, Kalappa SG. Relative efficacy of pimecrolimus cream and triamcinolone acetonide paste in the treatment of symptomatic oral lichen planus. Indian journal of dentistry. 2015 Jan;6(1):14

20. Siponen M, Huuskonen L, Kallio, Pulkkinen S, Nieminen P, Salo T. Topical tacrolimus, triamcinolone acetonide, and placebo in oral lichen planus: a pilot randomized controlled trial. Oral diseases. 2017 Jul;23(5):660-8.

21. Lozada-Nur FI, Sroussi HY. Tacrolimus powder in Orabase $0.1 \%$ for the treatment of oral lichen planus and oral lichenoid lesions: An open clinical trial. Oral Surg Oral Med Oral Pathol Oral Radiol Endod 2006; 102(6): 744-9. 